Volume 3 • Nomor 1 • Oktober 2019

Pege (Hal.) : $26-35$

(C) Universitas Pamulang

JL.Surya Kencana No.1 Pamulang, Tangerang Selatan - Banten

Telp. (021) 7412566, Fax (021) 7412491

website. : Email : jurnalmarketing.unpam@gmail.com

\title{
Analisa Penentu Keputusan Pembelian Konsumen Terhadap Produk Online (Pada Masyarakat Jabodetabek)
}

\author{
Yuga Pratama ${ }^{1}$ \\ Universitas Pamulang, email yugamild@gmail.com
}

\begin{abstract}
Abstrak. Penelitian ini membahas tentang perilaku keputusan pembelian konsumen terhadap produk online. Penelitian ini bertujuan untuk: (1) menentukan peringkat media e commerce dan alasan penentu apa saja yang di gunakan masyarakat Jabodetabek dalam mengambil keputusan pembelian atau belanja produk online, (2) mengetahui faktor faktor bauran pemasaran yaitu produk, promosi, harga, lokasi atau tempat dan promosi yang mempengaruhi keputusan pembelian produk online pada masyarakat di Jabodetabek.

Penelitian ini menggunakan metode analisis regresi linier berganda dengan menggunakan aplikasi Stata 10. Populasi penelitian adalah seluruh masyarakat di Jabodetabek dengan sampel sebanyak 100 responden.

Hasil dari penelitian ini bahwa $100 \%$ responden melakukan belanja online dengan alasan proses yang mudah dengan pilihan media e commerce 3 (tiga) peringkat teratas yaitu shopee, tokopedia dan lazada. Peringkat pertama produk yang menjadi pilihan masyarakat Jabodetabek adalah fashion yang meliputi baju, tas dan sepatu untuk digunakan secara pribadi dengan metode pembayaran yang paling sering digunakan adalah metode transfer antar bank. Pada faktor- faktor bauran pemasaran yang mempengaruhi keputusan pembelian belanja online, hasilnya menunjukkan bahwa variabel proses dan promosi berpengaruh terhadap keputusan pembelian belanja online sedangkan produk, harga, lokasi dan people (manusia) tidak berpengaruh terhadap keputusan pembelian online di Jabodetabek
\end{abstract}

\section{Keywords: Belanja Online; Bauran Pemasaran; Keputusan pembelian.}

Abstract. This study discusses the behavior of consumer purchasing decisions on online products. This study aims to: (1) determine the ranking of e-commerce media and the determine of Jabodetabek Community uses in making online product purchase decision, (2) find out the marketing moix factors namely products, promotions, price, location, people and process which influences online product purchasing decisions for communities in Jabodetabek

The analytical method used is multiple linear regression using the Stata 10 application. The study population was all communities in Jabodetabek with a sample of 100 respondents.

The results of this study that $100 \%$ of respondents do online shopping for easy process reasons with the choice of media e commerce top 3 (three) ranks, are shopee, tokopedia and lazada. The first rating of products that are the choice of the Jabodetabek community is fashion which includes clothes, bags and shoes for personal use with the payment method most often used is the method of transfer between banks. On the marketing mix factors that influence online shopping purchasing decisions, the results show that process and promotion variables influence the purchasing decisions of online shopping while the products, prices, locations and people do not affect the online purchasing decisions in Jabodetabek.

Key words : Online Shopping; e commerce; Marketing Mix; Purchase Decision 


\section{A. PENDAHULUAN}

Transaksi menggunakan E commerce di Indonesia semakin diminati, hal ini berdasarkan data Kominfo (2019) bahwa 7 persen dari 73 juta orang pengguna internet aktif di Indonesia menggunakan internet untuk transaksi jual beli produk. Laporan Perdagangan Digital oleh Hinrich Foundation (2019), memprediksi perkembangan transaksi e-commerce dapat menciptakan peluang ekonomi senilai 2.305 triliun rupiah bagi Indonesia pada tahun 2030 . Indonesia saat ini merupakan Negara 10 terbesar pertumbuhan e-commerce dengan pertumbuhan 78 persen dan berada di peringkat pertama, yang disusul kemudian oleh Meksiko.

Tabel 1. 10 Rangking Teratas e commerce di Indonesia Quartal 12019

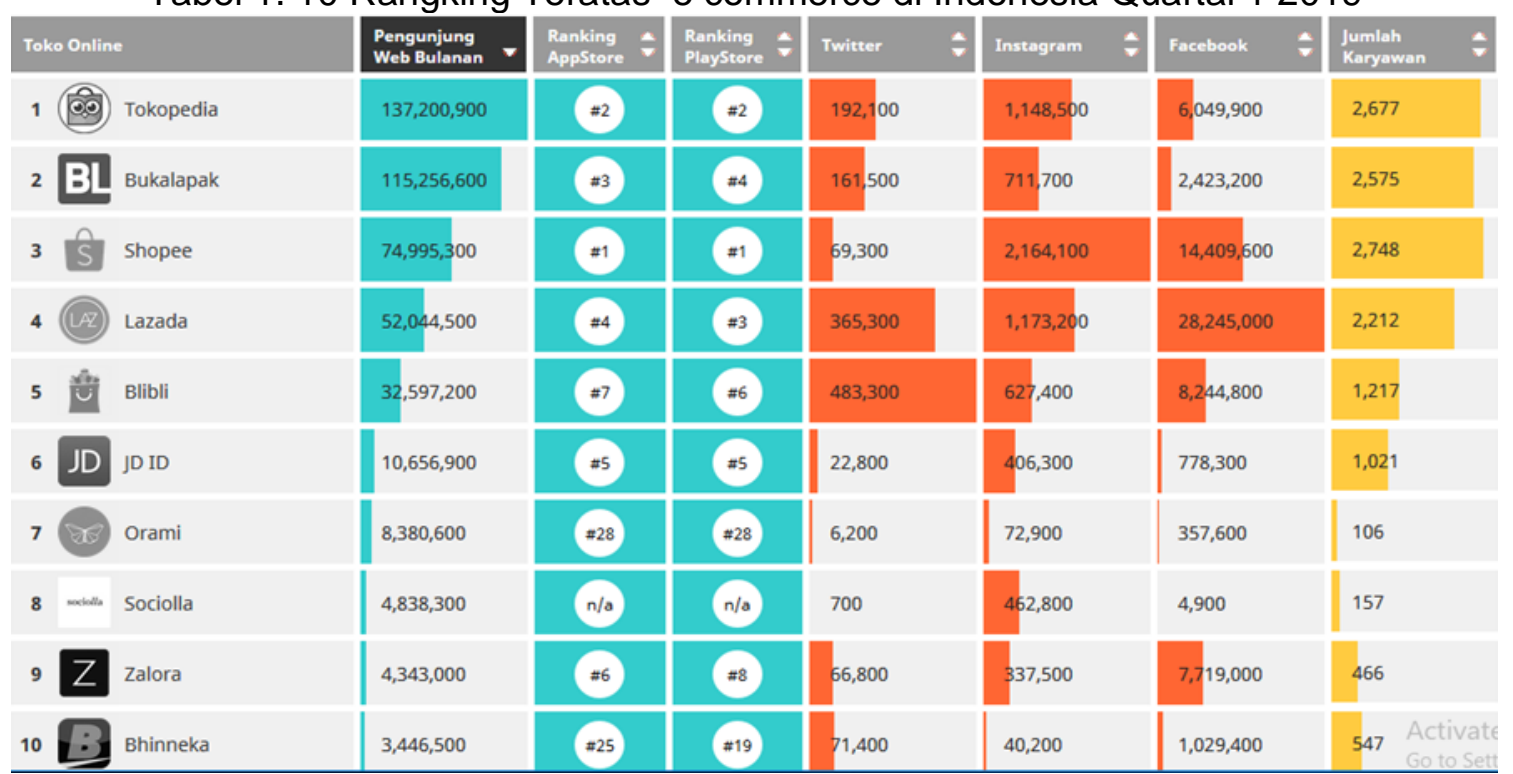

Sumber : iprice.go.id (2019)

Peta e-commerce Indonesia mengurutkan pemain besar e-commerce berdasarkan rata-rata pngunjung website di setiap kuartal, rangking aplikasi, pengikut media social, dan jumlah karyawan. Peringkat pertama diduduki oleh Tokopedia, tercatat memiliki jumlah kunjungan 137 juta per bulan dengan jumlah karyawan 2.667 orang. Sementara posisi kedua ditempati Bukalapak dengan jumlah kunjungan 115 juta per bulan dengan jumlah karyawan 2.575 orang. Sedangkan posisi ketiga dan keempat dikuasai marketplace regional yaitu shopee dan Lazada. Lazada menempati pengikut media social facebook tertinggi sebanyak 28 ribu orang.Sedangkan shopee menempati posisi pertama berdasarkan playstore dan pengikut media social instagram.

Perkembangan perdagangan elektronik di Indonesia, tidak lepas dari perkembangan perdagangan elektronik di wilayah ibukota dan sekitarnya yaitu JABODETABEK. Dimana Jabodetabek merupakan daerah pemusatan terhadap pembangunan dan pertumbuhan ekonomi yang berada pada wilayah sekitar ibukota DKI jakarta. Berdasarkan Data Badan Pusat Statistik pada tahun 2017 Pertumbuhan penduduk di JABODETABEK sudah mencapai 31.612.896 jiwa. Maka hal ini menjadi dasar penentuan penelitian ini fokus pada wilayah JABODETABEK yang memiliki potensi yang sangat baik bagi perkembangan perekonomian. 
Berdasarkan permasalahan diatas, maka penelitian ini membahas tentang perilaku keputusan konsumen di dalam menentukan pilihannya berbelanja dengan media online.

Berdasarkan uraian diatas, permasalahan yang akan diteliti yaitu : Apa saja aspek aspek penggunaan belanja online yang dilakukan oleh masyarakat Jabodetabek? Apakah terdapat pengaruh bauran pemasaran terhadap keputusan pembelian produk online?

Penelitian ini bertujuan untuk mengetahui unsur apa saja dalam penggunaan belanja online yang dilakukan oleh masyarakat Jabodetabek dan bagaimanakah pengaruh bauran pemasaran yang terdiri dari produk, harga, lokasi, promosi, manusia dan proses terhadap keputusan pembelian produk online

\section{B. KAJIAN LITERATUR}

Bauran Pemasaran

Kotler (2005: 17) menyebutkan bahwa dalam mencapai tujuan pemasaran , perusahaan menggunakan seperangkat alat pemasaran yang disebut dengan bauran pemasaran. Unsur unsur bauran pemasaran tersebut meliputi Product, Price, Promotion dan Place. Pada Produk terdapat kualitas, desain, variasi produk, layanan dan jaminan sedangkan harga merupakan harga uyang dibayarkan, termasuk bila ada potongan atau diskon. Promosi melingkupi iklan dan pemasaran sedangkan tempat (Place) melingkupi cakupan pasar. Pada pemasaran Jasa, Booms \& Bitner (1981) terdapat pendekatan 7 P yang menjadi unsure tambahan dari $4 \mathrm{P}$, yaitu (1) people (orang), yaitu mereka yang melakukan transaksi baik secara langsung atau tidak langsung terkait dengan pelayanan (2) process (proses), yaitu prosedur atau alur aktivitas pelayanan, dan (3) Physical evidence (tata letak secara fisik), yaitu lingkungan dimana proses pelayanan penjualan terjadi.

Keputusan pembelian

Inti dari pengambilan keputusan konsumen (consumen decision making) menurut Nugroho J Setiadi (2010:332) adalah proses memperoleh informasi dan melakukan kombinasi pilihan alternative serta memilih salah satu diantara pilihan tersebut. Hasil dari proses merupakan perilaku pelanggan dalam melakukan sebuah pilihan

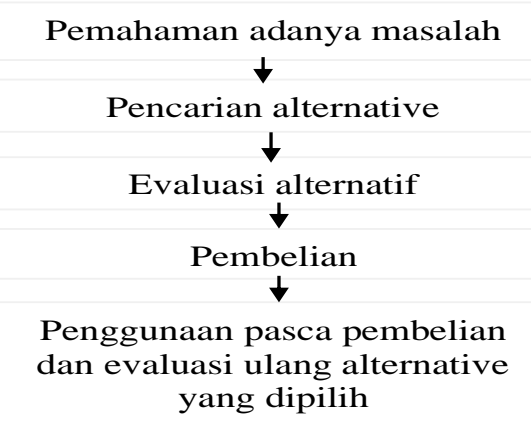

Sumber: Kotler \& Keller (2019:185)

Gambar 2. Model Lima Tahap Proses Pembelian Konsumen 


\section{METODOLOGI PENELITIAN}

Penelitian ini terdiri dari dua bagian yaitu analisis unsur penggunaan jasa belanja online dan analisis faktor-faktor yang mempengaruhi keputusan pembelian produk online. Penelitian ini merupakan penelitian deskriptif kuantitatif, dengan mendeskripsikan fenomena yang ada dan menggunakan metode regresi berganda untuk mengetahui faktor faktor yang mempengaruhi keputusan pembelian produk.

Adapun model regresi dalam penelitian ini, yaitu :

$$
\mathrm{Y}=\mathrm{a}+\mathrm{b}_{1} \mathrm{X}_{1}+\mathrm{b}_{2} \mathrm{X}_{2}+\mathrm{b}_{3} \mathrm{X}_{3}+\mathrm{b}_{4} \mathrm{X}_{4}+\mathrm{b}_{5} \mathrm{X}_{5}+\mathrm{b}_{6} \mathrm{X}_{6}
$$

\section{Keterangan :}

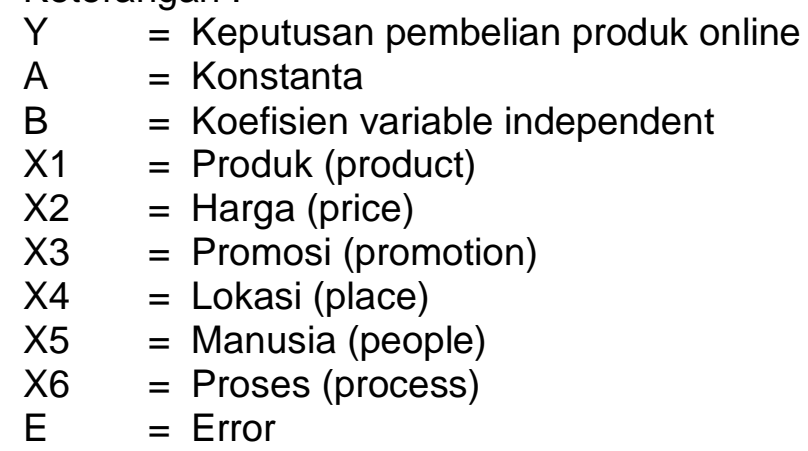

Daerah penelitian ini meliputi daerah Jabodetabek. Data Populasi jumlah masyarakat Jabodetabek berdasarkan Badan Pusat Statistik tahun 2017 adalah 31.612 .893 jiwa. Pengambilan sampel yang digunakan dalam penelitian ini adalah teknik probability sampling. Rumus Slovin menurut Sugiyono (2010: 63) dengan menggunakan rumus :

$$
\left(n=\frac{N}{1+N e^{2}}\right)
$$

\section{Dimana :}

$$
\begin{aligned}
& \mathrm{N} \quad \text { = jumlah anggota sampel } \\
& \mathrm{N} \quad \text { = jumlah anggota populasi } \\
& \mathrm{E} \quad=\text { error level (tingkat kesalahan } 0,10) \\
& \text { Maka hasil perhitungan atas besarnya sampel pada penelitian ini adalah: } \\
& n=\frac{31.612 .893}{1+31.612 .893 \times 0.1^{2}} \quad n=99,9 \text { atau } 100 \text { responden }
\end{aligned}
$$

Desain kuesioner penelitian terdiri dari unsur aktifitas penggunaan jasa belanja online dan perilaku konsumen. Unsur penggunaan jasa belanja online terdiri dari: (1) Tipe penggunaan belanja online (2) Jenis Produk (3) Tujuan penggunaan produk (4) Tipe pembayaran. Sedangkan unsur perilaku konsumen terdiri dari unsur marketing-mix dan keputusan pembelian. Metode analisis terhadap sikap dan perilaku masyarakat dalam memilih belanja produk online, menggunakan analisis statistik deskriptif berupa tabel, rata-rata dan frekuensi, sementara aspek perilaku konsumen dalam keputusan pembelian dianalisa menggunakan regresi berganda. 


\section{HASIL DAN PEMBAHASAN}

Karakteristik Responden

Hasil penelitian penyebaran kuesioner pada masyarakat Jabodetabek menunjukkan bahwa dari total responden sebanyak 100 orang , responden dalam usia produktif berjumlah $89 \%$ (89 orang) sisanya $11 \%$ berada dalam kategori tidak produktif. Berdasarkan jenis kelamin, wanita (53\% atau 53 orang) mendominasi jumlah responden sedangkan tingkat pendidikan terakhir responden terdiri dari lulusan sarjana $52 \%$ atau sebanyak 52 orang, lulusan SMA sebanyak $24 \%$, diploma sebanyak $20 \%$ dan $4 \%$ atau 4 orang berpendidikan pascasarjana.

Dilihat dari pekerjaan, mayoritas sebagai karyawan sebanyak $41 \%$ atau 41 orang, diikuti oleh pelajar dan mahasiswa sebanyak $18 \%$, wirausaha $12 \%$ atau 12 orang dan sisanya sebanyak $29 \%$ (29 orang) merupakan ibu rumah. Selanjutnya, responden yang berpenghasilan dibawah 3 juta sebanyak $13 \%$ (13 orang), berpenghasilan diatas 3 juta perbulan berjumlah $34 \%$ atau 34 orang, $37 \%$ berpenghasilan diatas 5 juta perbulan dan 16 $\%$ berpenghasilan diatas 10 juta perbulan.

Identifikasi Penggunaan Jasa Belanja Online

Hasil penelitian ini menemukan bahwa hampir setiap masyarakat di jabodetabek pernah melakukan transaksi belanja melalui media online, dengan alasan bahwa belanja online memberikan proses yang mudah, murah dan banyak promosi. Masyarakat jabodetabek melakukan belanja online banyak adalah membeli barang atau produk fashion yang meliputi baju, tas dan sepatu, dengan metode pembayaran yang paling banyak digunakan adalah metode transfer antar bank.

Media online yang menjadi pilihan masyarakat jabodetabek adalah Shopee di peringkat pertama sebesar 29 5, di susul oleh Tokopedia $24 \%$ dan lazada sebesar $15 \%$, adapun melalui Instagram hanya $10 \%$ saja. Adapun media social facebook saat ini sudah tidak menjadi pilihan untuk berbelanja online karena hanya $1 \%$ yang menggunakan Facebook untuk berbelanja, hal ini karena facebook digunakan untuk berbagi pengalaman sehari hari, bukan untuk berbelanja. Berikut rangking media online berdasarkan hasil penelitian.

Tabel 2. Rangking Media Belanja Online Pada masyarakat jabodetabek (2019)

\begin{tabular}{|c|l|c|}
\hline No Urut & Media Belanja Online & Persentase \\
\hline 1 & Shopee & $29 \%$ \\
\hline 2 & Tokopedia & $24 \%$ \\
\hline 3 & Lazada & $15 \%$ \\
\hline 4 & Instagram & $10 \%$ \\
\hline 5 & Bukapakak & $13 \%$ \\
\hline 6 & Blibli, zilingo & $8 \%$ \\
\hline 7 & Facebook & $1 \%$ \\
\hline
\end{tabular}


Media online yang menjadi pilihan masyarakat jabodetabek adalah Shopee di peringkat pertama sebesar 29 5, di susul oleh Tokopedia $24 \%$ dan lazada sebesar $15 \%$, adapun melalui Instagram hanya $10 \%$ saja. Adapun media social facebook saat ini sudah tidak menjadi pilihan untuk berbelanja online karena hanya $1 \%$ yang menggunakan Facebook untuk berbelanja, hal ini karena facebook digunakan untuk berbagi pengalaman sehari hari, bukan untuk berbelanja. Berikut rangking media online berdasarkan hasil penelitian.

Tabel 3. Rangking Produk Pilihan Belanja Online Pada masyarakat jabodetabek (2019)

\begin{tabular}{|c|l|c|}
\hline No Urut & Media Belanja Online & Persentase \\
\hline 1 & Fashion & $65 \%$ \\
\hline 2 & Peralatan rumah tangga & $9 \%$ \\
\hline 3 & Elektronik & $10 \%$ \\
\hline 4 & Aksesoris kendaraan & $5 \%$ \\
\hline 5 & Perlengkapan bayi & $4 \%$ \\
\hline 6 & Kosmetik & $7 \%$ \\
\hline
\end{tabular}

Berdasarkan tabel 3, produk yang menjadi pilihan responden atau masyarakat di wilayah jabodetabek dalam berbelanja online paling banyak adalah produk fashion meliputi baju anak, baju dewasa, baju muslim, tas dan sepatu. Pilihan kedua yang diminati oleh masyarakat Jabodetabek adalah alat elektronik, baru kemudian disusul oleh peralatan rumah tangga dan kosmetik.

Faktor faktor Bauran Pemasaran Terhadap Keputusan Pembelian Online

Berdasarkan pengujian terhadap faktor faktor bauran pemasaran yang telah dilakukan dengan menggunakan metode regresi linear berganda dengan menggunakan Stata 10, diperoleh hasil dibawah ini :

Tabel 4. Hasil Uji Regresi

\begin{tabular}{lllll}
\hline Variabel & Koefisien $\beta$ & $\mathrm{P}$ value & thitung & Keterangan \\
\hline Konstanta (C) & 5,056296 & 0,077 & 1,79 & \\
Product (X1) & 0,2801648 & 0,105 & 1,64 & Tidak Signifikan \\
Price (X2) & 0,0380128 & 0,735 & 0,34 & Tidak Signifikan \\
Place (X3) & $-0,0765252$ & 0,442 & $-0,77$ & Tidak Signifikan \\
Promotion (X4) & 0,1246411 & $0,077^{*}$ & 1,79 & Signifikan \\
People (X5) & 0,2098706 & 0,158 & 1,42 & Tidak Signifikan \\
Process (X6) & 0,3583091 & $0,024^{\star *}$ & 2,30 & Signifikan \\
\hline R Square & 0,3558 & & & \\
F-Statistic & 6,49 & & & \\
Prob (F- Statistic) & 0,0000 & & & \\
\hline
\end{tabular}


Berdasarkan tabel 4, didapatkan sebuah persamaan model regresi seperti di bawah ini :

$Y=5,0563+0,2802 X 1+0,0380 X 2-0,0765 X 3+0,1246 X 4+0,2099 X 5+0,3583 X 6+e$

Nilai konstanta yang dihasilkan adalah sebesar hasil 5,056296 yang diperoleh menunjukan bahwa ketika Produk (Product), harga (Price), Lokasi (Place), Promosi (Promotion), Manusia (People) dan Proses (Process) dianggap tetap atau konstan maka terjadi perubahan variabel dependen adalah sebesar 5,0563, yang berarti keputusan pembelian masyarakat Jabodetabek akan mengalami kenaikan sebesar 5,0563 satuan.

Media belanja online yang saat ini digunakan adalah E-commerce yang system kerjanya sangat bergantung pada internet dan teknologi informasi, Hasil penelitian menunjukkan bahwa Shopee, Tokopedia dan Lazada menempati urutan tertinggi penggunaan $\mathrm{E}$ commerce di Jabodetabek.

Berdasarkan hasil uji statistik, secara parsial variabel produk (Product) tidak berpengaruh terhadap keputusan pembelian online pada masyarakat di Jabodetabek. Hal tersebut dapat dilihat dari nilai $p$-value sebesar 0,105 lebih besar dari $\alpha$ atau tingkat kepercayaan sebesar 0,05 .

Nilai dari sebuah produk adalah manfaat yang dapat memenuhi kebutuhan konsumen. Sebelum melakukan proses keputusan pembelian, konsumen biasanya mencari informasi terkait produk yang akan dibeli, berdasarkan pertimbangan variasi model, ukuran, warna dan kualitas produk berdasarkan foto atau keterangan yang ditampilkan Namun, pada saat belanja online barang tersebut tidak dapat dilihat secara langsung sehingga terkadang barang yang diterima berbeda dengan yang di gambar. Pada beberapa produk, merek juga dapat menjadi pertimbangan apakah barang tersebut original atau tiruan. Penelitian ini menunjukkan bahwa produk tidak mempengaruhi keputusan berbelanja online, karena masyarakat sudah dapat menerka bagaimana kualitas produk berdasarkan berbagai pengalaman yang telah mereka alami, bahwa ada beberapa produk yang sama persis seperti toko offline, atau produk kualitas baik dengan harga mahal namun barang asli dan produk tiruan dengan kualitas rendah.

Variabel harga (Price) tidak berpengaruh terhadap keputusan pembelian online pada masyarakat di Jabodetabek. Hal tersebut dapat dilihat dari nilai $p$-value sebesar 0,173 lebih besar dari $\alpha$ atau tingkat kepercayaan sebesar 0,05 . Harga merupakan pengorbanan dalam bentuk uang yang dibayarkan untuk membeli produk online oleh konsumen. Harga pada produk online dapat diketahui dengan jelas, pasti dan sangat beragam tergantung kualitas produk. Penelitian ini menunjukkan bahwa harga tidak berpengaruh terhadap keputusan pembelian, yang berarti bahwa masyarakat jabodetabek tidak keberatan atas nominal harga yang tertera di menu penawaran asal sesuai dengan kualitas produk. Kebanyakan responden pada penelitian ini adalah karyawan, maka dapat dipahami sesungguhnya konsumen tidak cukup memiliki waktu dalam berbelanja dikarenakan bekerja, sehingga alternative yang sangat mudah adalah berbelanja online tanpa mempertimbangkan harga, karena banyak sekali pilihan harga yang dapat dipilih oleh konsumen pada produk yang sama.

Variabel lokasi (Place) tidak berpengaruh terhadap keputusan pembelian online pada masyarakat di Jabodetabek. Hal tersebut dapat dilihat dari nilai $p$-value sebesar 0,442 lebih besar dari a atau tingkat kepercayaan sebesar 0,05. Place disini merupakan saluran 
distribusi dalam menyalurkan produk dari suplier kepada pembeli atau konsumen. Namun hal ini tidak menjadi bahan pertimbangan bagi konsumen online, konsumen yakin bahwa barang aman dan cepat sampai ke tangan mereka tidak menjadi persoalan dimana lokasi penjual dan bagaimana distribusinya, karena saat ini sangat terbantu dengan pengiriman barang melalui paket dengan ongkos kirim yang terjangkau ataupun pengiriman ojek online.

Promosi atau iklan produk online dapat dilakukan dengan media sosial baik facebook, instagram, namun pada e commerce beberapa sering mempromosikan iklan nya melalui media televisi, hal ini bertujuan agar konsumen mengetahui perkembangan prosuk dan menjaring pembeli selaku target pasar baik konsumen lama maupun baru agar melakukan pembelian berulang kali bahkan dalam jumlah lebih banyak. Variabel promosi (Promotion) berpengaruh secara signifikan terhadap keputusan pembelian online pada masyarakat di Jabodetabek. Hal tersebut dapat dilihat dari nilai p-value sebesar 0,077 lebih besar dari $\alpha$ atau tingkat kepercayaan sebesar 0,10 . Promosi yang saat ini dilakukan oleh para perusahaan e-commerce adalah cash back, diskon hingga penjualan dengan harga $\mathrm{Rp} 1$ untuk produk senilai ratusan juta. Dengan berkembangnya promosi maka diharapkan konsumen mengetahui adanya produk baru dan termotivasi agar membeli suatu produk. Penelitian ini mendukung penelitian sebelumnya yaitu penelitian SI.Triyaningsih (2010), bahwa Pemasaran melalui online marketing dipandang baik karena memberikan beberapa keunggulan mempunyai diantaranya adalah praktis, cepat, mudah, dan bahkan hemat karena tanpa harus mengeluarkan biaya. mendukung juga penelitian dari Mujiyana (2013) bahwa program iklan atau promosi dapat mempengaruhi keputusan pembelian dengan proses yaitu konsumen menerima informasi, sehingga konsumen tertarik dan memperhatikan selanjutnya melakukan keputusan pembelian.

Variabel manusia (People) tidak berpengaruh terhadap keputusan pembelian online pada masyarakat di Jabodetabek. Hal tersebut dapat dilihat dari nilai p-value sebesar 0,158 lebih besar dari $\alpha$ atau tingkat kepercayaan sebesar 0,05 . Dalam penjualan online konsumen dan penjual tidak bertemu secara langsung, manusia tidak lagi menjadi jaminan dari pebelian, maka dari itu dapat dipahami bahwa manusia (people) tidak mempengaruhi keputusan pembelian produk online.

Variabel proses (Process) berpengaruh signifikan dan memiliki arah positif terhadap keputusan pembelian online pada masyarakat di Jabodetabek dengan tingkat probabilitas 0,024 atau dapat dikatakan dibawah signifikansi level 0,05. Proses belanja Online yang dirasakan oleh konsumen adalah kemudahan pembelian, dimana akses melalui internet, toko buka 24 jam. Proses pada E commerce atau Perdagangan elektronik di mulai dari proses pengembangan, penjualan atau pemasaran, pengiriman barang, pelayanan terhdap konsumen, dan pembayaran yang dilakukan melalui berbagai fitur baik transfer, virtual account dan lain sebagainya. Proses ini juga terjadi dengan adanya dukungan dari jaringan para mitra bisnis baik lokal maupun mitra di seluruh dunia.

\section{E. KESIMPULAN}

Kesimpulan

Seratus persen responden melakukan belanja online dengan alasan proses yang mudah dengan pilihan media e commerce 3 (tiga) peringkat teratas yaitu shopee, tokopedia dan lazada. Peringkat pertama produk yang menjadi pilihan masyarakat Jabodetabek adalah 
fashion yang meliputi baju (baju bayi, baju anak, baju dewasa dan baju muslim), tas dan sepatu untuk digunakan secara pribadi dengan metode pembayaran yang paling sering digunakan adalah metode transfer antar bank. Pada faktor- faktor pengaruh bauran pemasaran yang meliputi faktor produk, harga, promosi, lokasi, manusia dan proses terhadap keputusan pembelian belanja online, hasilnya menunjukkan bahwa variabel proses dan promosi berpengaruh terhadap keputusan pembelian belanja online. Sedangkan faktor bauran pemasaran lainnya meliputi produk, harga, lokasi dan people (manusia) tidak berpengaruh terhadap keputusan pembelian online di Jabodetabek.

Proses yang dirasakan oleh responden adalah kemudahan yang didapat dengan berbelanja online bahwa konsumen cukup berbelanja menggunakan handphone genggam atau sarana lainnya yang dapat dilakukan dengan internet dengan cara membuka aplikasi atau alamat web penjual kemudian klik membeli, dianjutkan dengan melakukan pembayaran melalui mobile banking untuk transfer dan meninjau proses pembelian hingga sampai ke tangan konsumen.

\section{Saran}

Saran saran berdasarkan penelitian ini, yaitu :

a. Bagi Konsumen dalam melakukan keputusan pembelian, harus memperhatikan unsur utama kehidupan yaitu kebutuhan pokok, agar terhindar dari belanja produk yang sia sia hanya berdasarkan keinginan atau penasaran belaka. b. Bagi pemerintah perlu terus menggalakkan UMKM online agar konsumen tidak konsumtif namun juga berpikir untuk membuka peluang usaha dengan memanfaatkan kemudahan pemsaran online yang berkembnag saat ini. c. Bagi perusahaan penjual, dapat melakukan inovasi yang berkelanjutan, menciptakan produk yang berkualitas dan ramah lingkungan sehingga menjadikan nilai jual yang lebih baik kepada masyarakat dan alam sekitar.

\section{DAFTAR PUSTAKA}

Farida, I., Tarmizi, A., \& November, Y. (2016). Analisa Pengaruh Bauran Pemasaran 7 P Terhadap Kepuasan Pelanggan Pengguna Gojek Online. Jurnal Riset Manajemen dan Bisnis , 31 - 40.

Hermawan, A. (2012). Komunikasi Pemasaran. Jakarta: Erlangga.

Hinrich Foundation.com. (2019). Retrieved 2019, from How Indonesia can capture the digital trade opportunityat home and abroad: http://hinrichfoundation.com

iprice.go.id. (2019). Retrieved july monday, 2019, from peta e-commerce Indonesia: http://www.iprice.go.id

Jennex, M. E., Amoroso, D., \& Adelakun, O. (2004). E commerce Insfrastructure Success Factors For Small Companies in Developing Economies. Electronic Commerce Research ABI/INFORM Global USA , 263.

Kominfo.go.id. (2019). Retrieved from Program Prioritas Tata Kelola Internet: http://www.kominfo.go.id

Kotler, P. (2005). Manajemen Pemasaran. Jakarta: Indeks Kelompok Gramedia. 
Kotler, \& Keller. (2009). Manajemen Pemasaran. Jakarta: Indeks Kelompok Gramedia. Mujiyana, \& Elissa, i. (2013). Analisa Faktor Faktor Yang Mempengaruhi Keputusan Pembelian Via Internet Pada Toko Online. Jurnal Manajemen

Putri, n. a. (2016). Desain strategi pemasaran online pada FULLUS fashion melalui evaluasi benchmarking. performa jurnal manajemen dan start up bisnis Universitas Ciputra Surabaya .

Setiadi, N. j. (2010). Perilaku Konsumen. Jakarta: Prenada Media Group.

Sharma, G., \& Lijuan, W. (2015). The Effects Of Online Service Quality Of E Commerce Websites On User Satisfaction. Electronc Library Emerald Group Publishing Limited , 468-485.

Smith, M. D., \& Brynjolfsson. (2001). Consumer Deciision Making At An Internet Shopbot. Sosial Science Reseacrh Network Electronik Paper Collection .

Statistik, B. P. (2019).

Su, X. (2006). Interpolar Pricing With Strategic Customer Behaviour. Haas School Of Business University Of California Berkeley .

Sugiyono. (2010). Metode Penelitian Kuantitatif dan Kualitatif. Bandung: Alfabeta.

Sukotjo, H., \& Radix, S. (2010). Analisa Marketing Mix 7 P (Product, Price,Promotion, Place, Participant, Process dan physical Evidence) terhadap keputusan pembelian produk klinik kecantikan teta di Surabaya. Jurnal Mitra Ekonomi dan Manajemen Bisnis , 216228.

Triyaningsih, S. (2011). Dampak Online Marketing Melalui Facebook Terhadap Perilaku Konsumtif Masyarakat. Jurnal Ekonomi dan Kewirausahaan Fakultas Ekonomi Universitas Slamet Riyadi Surakarta , 172-177.

Yuniarti, Y. (2016). Pengaruh Kualitas Produk, Harga dan Kepercayaan Terhadap Keputusan Pembelian Produk Fashion Secara Online. Jurnal Penelitian Universitas Jambi Seri Humaniora , 27-37. 